\title{
The Influence of Storage Conditions on the Biochemical Composition and Morphology of Dablia Tubers
}

\section{Ioana CIOBANU ${ }^{1}$, Maria CANTOR ${ }^{1 *}$, Răzvan ŞTEFAN² ${ }^{2}$, Erzsebet BUTA ${ }^{1}$, Klara MAGYARI ${ }^{3}$, Monica BAIA ${ }^{3,4 *}$}

\author{
${ }^{1}$ University of Agricultural Sciences and Veterinary Medicine, Faculty of Horticulture, 3-5 Manastur Street, 400372 Cluj-Napoca, \\ Romania;ioanamica87@yahoo.com; marcantor@yahoo.com ("correspondingauthor); ebuta2008@yahoo.com \\ ${ }^{2}$ University of Agricultural Sciences and Veterinary Medicine, Faculty of Veterinary Medicine, 3-5 Manastur Street, 400372 Cluj-Napoca, \\ Romania; razstef@gmail.com \\ ${ }^{3}$ Babes-Bolyai University, Institute for Interdisciplinary Research in Bio-Nano-Sciences, 42 Treboniu Laurean Street, 400271 Cluj-Napoca, \\ Romania; klara.magyari@ubbcluj.ro \\ ${ }^{4}$ Babes-Bolyai University, Faculty of Physics, 1 Mihail Kogalniceanu Street, 400084 Cluj-Napoca, \\ Romania; monica.baia@phys.ubbcluj.ro (*orrespondingauthor)
}

\begin{abstract}
The aim of this study was to assess by means of biometric measurements and FT-IR and FT-Raman spectroscopic techniques the influence of storage conditions on the morphology and biochemical composition of Dablia tubers. Investigated samples belong to 'Kennemerland' and 'Red Pygmy' cultivars of the Dablia hybrida species, which were preserved over winter at $5-8{ }^{\circ} \mathrm{C}, 30-40 \%$ air humidity in different substrates: sand, sand and sawdust, peat and sawdust. The biometric parameters revealed that the peat and sawdust substrate is the most appropriate one for tubers storage, whereas the sand substrate is the least suitable one. The inulin signature was evidenced in all tuber samples as well as the changes of biochemical composition induced by different storage conditions. The analysis of the FT-IR and FT-Raman spectra demonstrated that the inulin accumulation inside the tubers is favourably influenced by the sand storage, and depends on the cultivar type. Moreover, it was established that the peat and sawdust substrate favours the polyacetylene formation inside the tubers probably because it facilitates the occurrence and development of pathogens inside the tuber. It was also found that the polyacetylene concentration increased, which is associated with the plant response to the pathogen invasion, depends on the cultivar type.
\end{abstract}

Keywords: biometric measurements, cultivars, FT-IR and FT-Raman spectra, inulin, plant storage organs, polyacetylenes

\section{Introduction}

The genus Dablia belongs to the Asteraceae family (Lord, 2003) and is one of the most popular ornamental plants in the world, and has more abundant flower colour variations than many other floricultural species (Draghia and Chelariu, 2011). The flower of this species contains an important amount of flavonoids including anthocyanins, butein and flavones as pigments in its petals (Muntean et al., 2011). Studies conducted by Nsabimana and Jiang (2011) showed that the Dablia tubers are rich in carbohydrates, fibers, proteins, essential minerals and vitamins. Some cultivars belonging to $D$. pinnata have edible tubers, which can be used in the human diet. The tubers of Dablia contain inulin, a natural renewable versatile polysaccharide reserve (Bernal et al., 2005) found in monocotyledonous and dicotyledonous families, but mainly in those belonging to the Asteraceae, Boraginaceae, Asparagus (Koruri, 2014), Liliaceae and Amaryllidaceae (Herrero, 2014).

Inulin was first isolated from the Inula belenium plant, from which it derives its name. The nutritional and functional attributes of inulin are very valuable, and consequently it has a remarkable number of food, pharmaceutical, chemical (LaraCortés et al., 2014), and industrial applications (Draghia and Chelariu, 2011). Inulin acts as a fat or sugar replacement and soluble dietary fiber (Lord, 2003; Saengthongpinit and Sajjaanantakul, 2005) in the food industry, having the advantage of very low caloric value (Ohno et al., 2013), and being also known as prebiotic (Zubaidah and Akhadiana, 2013; Kosasih et al., 2015). It is also used as a stabilizer, excipient or as an injectable for clinical measurement of kidney function, in pharmaceutical applications (Saengthongpinit and Sajjaanantakul, 2005; Deguchi et al., 2013). Moreover, inulin 
460

has important biological effects, being a potent complement pathway activator, when in a particulate form, having anticancer (Bernal et al., 2005; Koruri et al., 2014) and immunomodulatory properties. Some studies have shown that inulin stimulates the immune system of the body and reduces the incidence of colon cancer (Deguchi et al., 2013). All these investigations revealed the effect of inulin in the gastrointestinal tract, on constipation, on mineral absorption, and on glycemic level. In the chemical industry, inulin is used for the production of alcohols, including ethanol, or as a source of sugars, as precursors in the production of various chemicals, such as glycerol, found in the composition of detergents (Barclay et al., 2010). Given the importance and beneficial effects of inulin, there is an increasing interest in recent years for the use of inulin in processed foods because of its adaptable characteristics and suitability even for diabetics (Hakiki et al., 2015).

The molecular particularities of inulin differ depending on many factors, such as plant source, the climate and growing conditions, the harvesting maturity and the storage time after harvest (Baranska et al., 2013).

Because inulin is the main carbohydrate in Dablia tubers, it provides nourishment when the plant is entering the vegetative phase by contributing to the development of the new shoots. Thus, it can be said that carbohydrates stored in the tuberous roots (particularly inulin in the case of Dablia) ensures the perennial trait of the plant and has direct influence on early growth in the new season.

It is well known that both FT-IR and FT-Raman spectroscopic methods are successfully applied to the analysis of valuable plant substances (Gierlinger and Schwanninger, 2007). Both methods allow obtaining spectra that contain fingerprint bands of individual components. In contrast to other methods, these spectroscopic methods are nondestructive analytical techniques that enable the simple and rapid identification of biological materials by spectral fingerprinting, as well as characterization and biochemical interpretation related to environment and taxonomy (Zimmermann and Kohler, 2014).

The purpose of the present study was to obtain more precise information about the influence of the storage conditions on the biochemical composition of different Dablia tubers preserved over winter in various substrates by means of FT-IR and FT-Raman spectroscopy. The studied samples belong to 'Kennemerland' and 'Red Pygmy' cultivars, which belong to Dablia hybrida. The FT-IR and FT-Raman spectra of the tubers were recorded before and after keeping them in different substrates, and the changes induced by different storage conditions on the tubers biochemical composition, including primary and secondary metabolites, are discussed.

\section{Materials and Methods}

\section{Biologicalmaterial}

In order to determine the influence of the storage conditions on Dablia's biochemical composition, the 'Kennemerland' and 'Red Pygmy' cultivars belonging to Dablia bybrida species were used. The biological material was purchased from Botanical Garden "Alexandru Borza" ClujNapoca, Romania.

\section{Storage conditions}

Tubers were harvest from an open field in autumn (October) and the storage over winter was done in a cool place with a temperature of $5-8{ }^{\circ} \mathrm{C}$, and $30-40 \%$ air humidity until preforcing (end of March). Dablia tubers were kept during the winter, in the following substrates: sand, sand + sawdust (70\% $+30 \%)$ and peat + sawdust $(70 \%+30 \%)$. Peat was purchased in compressed form, packaged in Lithuania, with a grain size of 0-20 mm, disinfected, $\mathrm{pH}$ 5.5-6.5 and a containing fertilizer $\left(\mathrm{N}-\mathrm{P}_{2} \mathrm{O}_{5}-\mathrm{K}_{2} \mathrm{O}\right)$ of $1.7 \mathrm{~kg} / \mathrm{m}^{3}$. The sand was $2-20 \mathrm{~mm}$ and obtained from the bottom of waters. The sawdust originates from the deciduous wood processing. In each substrate, four tuberous roots of every cultivar were placed. Tubers were also stored under similar conditions of temperature and air humidity without any of the mentioned substrates.

The experiment was organized with 2 factors: a - cultivar, with 2 levels represented by the cultivars: 'Kennemerland' and 'Red Pygmy' and factor b - the storage conditions, with four levels: sand, sand + sawdust, peat + sawdust, no substrate.

The samples used for spectroscopic analysis were:

- tubers analyzed in spring (control)

- tubers stored in sand $(100 \%)$ over winter

- tubers stored in sand + sawdust $(70 \%+30 \%)$ over winter

- tubers stored in peat + sawdust $(70 \%+30 \%)$ over winter

- fresh tubers at harvest in autumn

- pure commercial inulin (for comparison).

\section{Biometric determinations}

At the beginning and at the end of the rest period of the plants the biometric parameters included root weight and the number of tubers per root on four tuberous roots for every cultivar maintained in each substrate and also on the tubers stored under similar conditions without any substrate were determined. By combining the two factors with 2 and respectively 4 levels resulted 8 experimental variants. Statistical interpretation of data was performed using Duncan test (Sestras et al., 2013).

\section{FT-IR and FT-Raman measurements}

FT-IR spectra were recorded on root sections with a JASCO IRT-5000 microscope coupled with a JASCO FTIR6200 spectrometer in reflection configuration in the 4000-700 $\mathrm{cm}^{-1}$ spectral range with a $4 \mathrm{~cm}^{-1}$ resolution, using the $32 \times$ Cassegrain objective to image a sample area of $\sim 50 \times 50 \mu \mathrm{m}^{2}$.

The FT-IR absorption spectrum of pure inulin sample (purchased from Alfa Aesar) was recorded with a JASCO 6200 spectrometer, at room temperature, in the $400-4000 \mathrm{~cm}^{-1}$ range with a spectral resolution of $4 \mathrm{~cm}^{-1}$, by using the $\mathrm{KBr}$ pellet technique.

FT-Raman spectra were recorded on both Dablia root sections and pure inulin sample by using a Bruker EQUINOX 55 spectrometer with an integrated FRA 160 Raman module, with a $4 \mathrm{~cm}^{-1}$ resolution. A radiation of $1064 \mathrm{~nm}$ was employed and the laser spot on the sample was about $0.1 \mathrm{~mm}$ in diameter.

FT-IR and FT-Raman spectra were recorded on sections from four tubers of each cultivar in order to assure the measurements reproducibility. 


\section{Results and Discussion}

\section{Biometric measurements}

The results obtained by assessing the weight of tuberous roots of both cultivars of Dablia bybrida before and after their storage in different substrates are presented in Table 1. In order to better evaluate the influence of the storage substrates on the tubers morphology and biochemical composition of some tubers were stored over winter in similar conditions without keeping them in any of the mentioned substrates. By looking at the data from Table 1 one can see that the weight of all roots decreased during the rest period, the highest root weight modification being observed for the tubers kept in none of the mentioned substrates. Thus, the root weight decrease was of 27.56\% and 29.3\% for 'Kennemerland' and 'Red Pygmy' cultivars, respectively. Moreover, among all investigated substrates the samples preserved in sand exhibited the highest weight loss during the winter for both cultivars, whereas the least was observed for the tubers maintained in peat and sawdust substrate. So, for sand storage the tuberous roots of 'Kennemerland' decreased over winter by $27 \%$ and those of the 'Red Pygmy' cultivar decreased by $22.93 \%$. In the case of peat and sawdust storage the roots experienced a weight decrease by $11.27 \%$ and $7.9 \%$ for 'Kennemerland' and 'Red Pygmy', respectively. Consequently, one can conclude that from the point of view of the root weight loss the peat and sawdust substrate is the most beneficial for tubers preservation.

Regarding root weight before winter storage (Table 1) the variant $V_{3}$ presented statistical differences from variants $V_{5}, V_{7}$ and $V_{8}$. Between the variants $V_{1}, V_{2}, V_{3}, V_{4}$ belonging to cultivar 'Kennemerland' there are registered differences in value but these are not ensured statistically. Differences in value can also be observed for the variants $V_{5}, V_{6}, V_{7}, V_{8}$ represented by the cultivar 'Red Pygmy', but these are not statistically significant. The highest value was registered for $\mathrm{V}_{6}$, with 0.17 $\mathrm{kg}$.

After the storage of the roots in different substrates over winter (Table 1 ) the variants $V_{1}, V_{2}, V_{3}, V_{4}$ were statistically different from $V_{8}$. For the cultivar 'Kennemerland' there are registered differences in value, the highest value being attributed to the variant $\mathrm{V}_{3}$ with $0.31 \mathrm{~kg}$. The cultivar 'Red Pygmy' doesn't present statistical differences but it can be noted $V_{6}$ and $V_{7}$ present the highest value.

The numbers of tubers per root was also evaluated for both cultivars before and after keeping them in different substrates, and the obtained results are presented in Table 2 . The number of tubers remained constant over winter for both cultivars and all substrates, except for the tubers of the 'Kennemerland' roots stored in sand that decreased from the mean value of 10.5 before storage to the mean values of 10 after the rest period. This result can be correlated with the fact that the most important weight decrease was observed for the tubers stored in sand. During the winter the tubers are dehydrating and so the number of tubers can decrease. It can be noted that the variants of the two cultivars register only differences in value both before and after winter storage, and these differences are not ensured statistically.

\section{FT-IR and FT-Raman analysis}

The investigations concerning the chemical composition of some garden Dablia tubers revealed that they are rich in carbohydrates, fiber and proteins, in spite of the considerable variability observed among cultivars (Nsabimana and Jiang, 2011). Consequently, the fingerprint bands of these components should be observed in the vibrational spectra.

Table 1. Weight values of the tuberous roots of Dablia hybrida cultivars before and after storage in different substrates

\begin{tabular}{|c|c|c|c|c|c|}
\hline \multirow{3}{*}{$\begin{array}{l}\text { No. } \\
\text { var. }\end{array}$} & \multirow{3}{*}{ Cultivar } & \multirow{3}{*}{ Substrate } & \multicolumn{2}{|c|}{ Root weight (kg) } & \multirow{3}{*}{$\begin{array}{l}\text { Root weight } \\
\text { difference (\%) }\end{array}$} \\
\hline & & & Before storage & After storage & \\
\hline & & & Mean & Mean & \\
\hline$V_{1}$ & \multirow{4}{*}{ 'Kennemerland' } & Sand & $0.31 \mathrm{AB}$ & $0.23 \mathrm{~A}$ & 27.00 \\
\hline $\mathrm{V}_{2}$ & & Sand + sawdust & $0.34 \mathrm{AB}$ & $0.27 \mathrm{~A}$ & 19.40 \\
\hline $\mathrm{V}_{3}$ & & Peat + sawdust & $0.36 \mathrm{~A}$ & $0.31 \mathrm{~A}$ & 11.27 \\
\hline $\mathrm{V}_{4}$ & & No substrate & $0.35 \mathrm{AB}$ & $0.26 \mathrm{~A}$ & 27.56 \\
\hline $\mathrm{V}_{5}$ & \multirow{4}{*}{ 'Red Pygmy' } & Sand & $0.16 \mathrm{C}$ & $0.12 \mathrm{AB}$ & 22.93 \\
\hline $\mathrm{V}_{6}$ & & Sand + sawdust & $0.17 \mathrm{ABC}$ & $0.14 \mathrm{AB}$ & 16.17 \\
\hline $\mathrm{V}_{7}$ & & Peat + sawdust & $0.15 \mathrm{C}$ & $0.14 \mathrm{AB}$ & 7.90 \\
\hline $\mathrm{V}_{8}$ & & No substrate & $0.16 \mathrm{BC}$ & $0.11 \mathrm{~B}$ & 29.30 \\
\hline \multicolumn{3}{|c|}{ DS 5\% } & $0.16-0.19$ & $0.14-0.16$ & - \\
\hline
\end{tabular}

Note: DS 5\% differences between any two values followed by at least one common letter are insignificant

Table 2. The number of tubers per roots of Dablia hybrida cultivars before and after storage over winter in different substrates

\begin{tabular}{|c|c|c|c|c|}
\hline \multirow{3}{*}{ No. var. } & \multirow{3}{*}{ Cultivar } & \multirow{3}{*}{ Substrate } & \multicolumn{2}{|c|}{ Number of tubers per root } \\
\hline & & & Before storage & After storage \\
\hline & & & Mean value $^{2}$ & Mean value $^{2}$ \\
\hline $\mathrm{V}_{1}$ & \multirow{4}{*}{ 'Kennemerland' } & Sand & $10.5 \mathrm{~A}$ & $10.0 \mathrm{~A}$ \\
\hline $\mathrm{V}_{2}$ & & Sand + sawdust & $10.5 \mathrm{~A}$ & $10.5 \mathrm{~A}$ \\
\hline $\mathrm{V}_{3}$ & & Peat + sawdust & $12.0 \mathrm{~A}$ & $12.0 \mathrm{~A}$ \\
\hline $\mathrm{V}_{4}$ & & No substrate & $10.5 \mathrm{~A}$ & $10.5 \mathrm{~A}$ \\
\hline $\mathrm{V}_{5}$ & \multirow{4}{*}{ 'Red Pygmy' } & Sand & $8.0 \mathrm{~A}$ & $8.0 \mathrm{~A}$ \\
\hline $\mathrm{V}_{6}$ & & Sand + sawdust & $7.75 \mathrm{~A}$ & $7.75 \mathrm{~A}$ \\
\hline $\mathrm{V}_{7}$ & & Peat + sawdust & $7.0 \mathrm{~A}$ & $7.0 \mathrm{~A}$ \\
\hline $\mathrm{V}_{8}$ & & No substrate & $9.75 \mathrm{~A}$ & $9.75 \mathrm{~A}$ \\
\hline \multicolumn{3}{|c|}{ DS 5\% } & $5.02-5.72$ & $4.85-5.52$ \\
\hline
\end{tabular}


The FT-IR and FT-Raman spectra of the tubers were recorded before and after storage in different substrates (Figs. 1 and 2). In order to better identify the fingerprint bands of the inulin molecule, FT-IR and FT-Raman spectra of the pure sample were also recorded, and are presented alongside the spectra recorded on Dablia tubers. By analyzing the spectra one can observe the inulin signature besides the changes of other active compounds induced by different storage conditions. As already mentioned, in order to better assess the influence of the storage substrates on the tubers' biochemical composition, some tubers were stored over winter in similar conditions without keeping them in any of the mentioned substrates. The FT-IR and FT-Raman spectra were also recorded on sections from these tubers and are presented in Figures 1 and 2 and denoted as "spring" spectra.

By comparing the spectra recorded from Dablia tubers with the FT-IR spectrum of the pure inulin sample (see Fig. 1A and $2 \mathrm{~A}$ ) one can identify the most enhanced absorption bands of the inulin from 936, 1030, 1130 and $1643 \mathrm{~cm}^{-1}$ in the tubers' spectra, whereas some shifts and changes of the relative

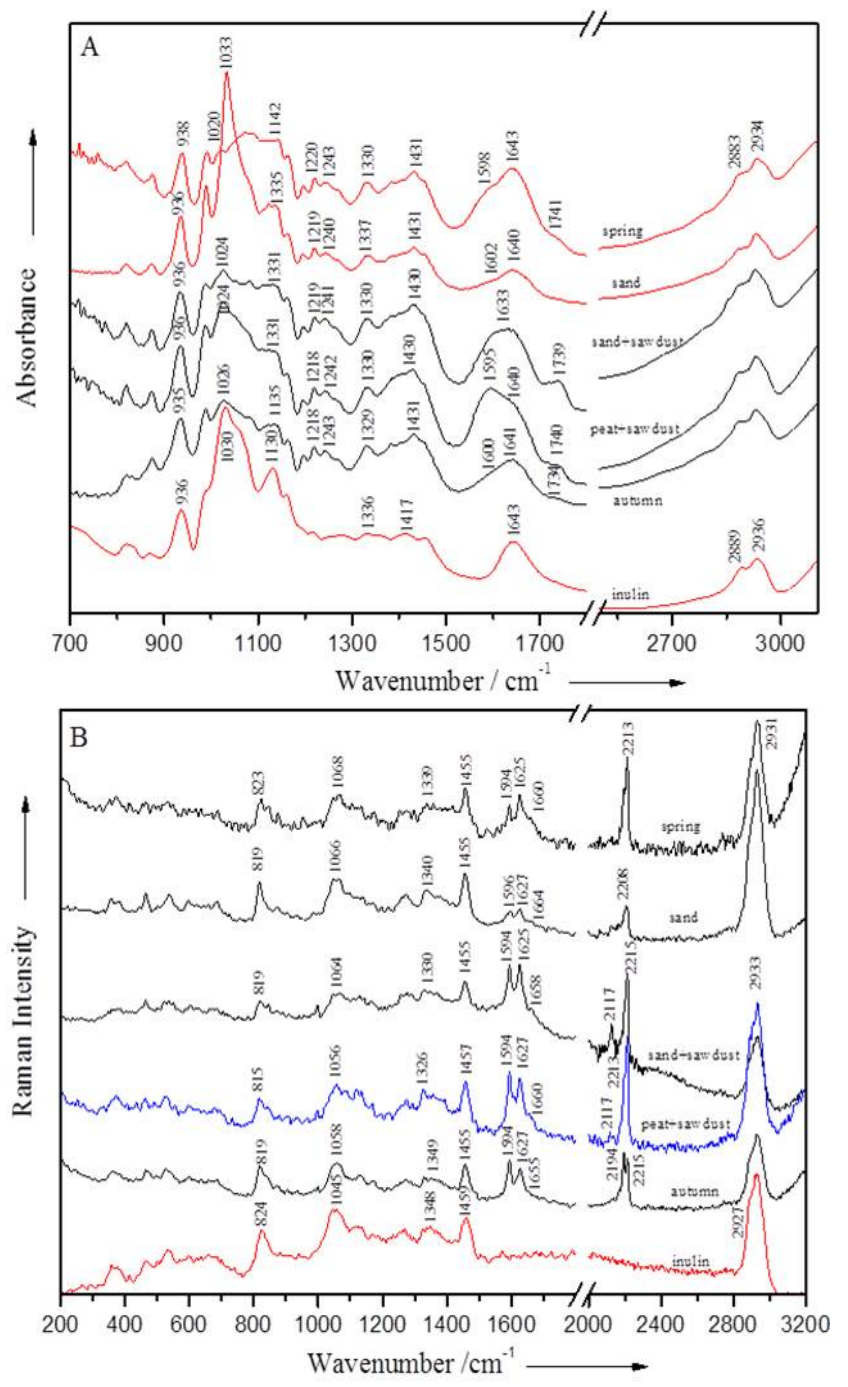

Fig. 1. FT-IR (A) and FT-Raman (B) spectra of 'Kennemerland' cultivar's tuber before and after storage over winter in different substrates as indicated. The inulin spectra are also presented for comparison purposes intensity of the bands can be also observed. However, close analysis of the spectra reveals that the sand substrate favours the inulin accumulation over winter in the tubers of both Dablia cultivar types, as the inulin bands intensity is the highest one in these spectra. Moreover, it was also observed that in the case of the 'Kennemerland' cultivar (see Fig. 1A) the peat + sawdust substrate also favours the inulin accumulation inside the tubers, whereas for the 'Red Pygmy' cultivar (see Fig. 2A) the inulin is accumulated inside the tubers kept in the sand + sawdust substrate, and even in those stored without any substrate, but in similar temperature and humidity conditions.

Currently the most important sources of inulin are: Chichorium intybus, Jerusalem artichoke and Dablia sp. (Machado et al., 1998; Kaur, 2002; Saengthongpinit and Sajjaanantakul, 2005; Hakiki et al., 2015) These three species belong to Asteraceae family and present high inulin levels of about $75 \%$ from the dry matter of the storage organ (Machado et al., 1998). It was determined in previous studies that particularly the tubers of Dablia are richer in inulin than other species like gembili and yam, while the inulin from Dablia presents higher solubility (Zubaidah and Akhadiana, 2013).

The close analysis of the FT-IR spectra of the tubers harvested in autumn reveals the signature of the vibrational modes of the main components. Thus, the cellulose vibrations give rise to the characteristic doublet around 1060 and 1125 $\mathrm{cm}^{-1}$, due to the asymmetric and symmetric C-O-C vibration, and the bands around 1330 and $1430 \mathrm{~cm}^{-1}$, due to the deformation vibration of the cellulose $\mathrm{CH}$ and $\mathrm{CH}_{2}$ groups, respectively (Schulz and Baranska, 2007; Roman et al., 2011b). The bands around 1220 and $1240 \mathrm{~cm}^{-1}$ are due to the lignin vibrations (Derkacheva and Sukhov, 2008). Lignin is a complex polyphenolic biomacromolecule consisting of coneferyl, sinapyl and p-coumaryl alcohols, and is a major component of the cell walls (Perera et al., 2012), which provides structural and mechanical integrity of the cell walls and recalcitrance to degradation or pathogenic attacks (Perera et al., 2011). Moreover, in the spectral range between 1590 and $1740 \mathrm{~cm}^{-1}$ one can see, beside the bands around $1640 \mathrm{~cm}^{-1}$ due to inulin vibration, three other absorption signals located around 1600, 1680 and $1740 \mathrm{~cm}^{-1}$. The bands around 1600 $\mathrm{cm}^{-1}$ are given by the stretching vibrations of the $\mathrm{C}=\mathrm{C}$ bonds from polyphenolic compounds, whereas the shoulders around $1680 \mathrm{~cm}^{-1}$ are due to the amide I vibrations indicating the proteins presence. The absorption signal recorded around 1740 $\mathrm{cm}^{-1}$ originates from pectin, and is assigned to the stretching vibration of the $\mathrm{C}=\mathrm{O}$ groups (Schulz and Baranska, 2007).

By comparing the FT-IR spectra recorded from tubers preserved in different substrates (see Figs. 1A and 2A) with the spectra of the tubers harvested in autumn significant changes of the relative intensities of some bands can be observed, which are related to modifications of the tuber's biochemical composition. Thus, one can see that the intensity of the bands assigned to cellulose vibrations is increasing in all FT-IR spectra. This behaviour is not surprising at all because cellulose is the principal constituent of the plant cell wall, and thus, its presence in all tissues is expected. Moreover, it is known that younger cells have a thin cell wall composed of polysaccharides and proteins with sporadically enclosed cellulose fibers. During cell aging process the secondary wall is formed and more cellulose is incorporated to make the wall stronger. The growing and thickening process of the cell wall give rise to higher amounts of polysaccharides, including pectin, to be 
deposited (Roman et al., 2011b). Accordingly, the intensity of the absorption band originating from pectin vibrations is increased mainly in the spectra recorded from 'Red Pygmy' tubers kept in different substrates as compared to the corresponding band from the spectrum recorded on autumn harvested tubers. Furthermore, the lignin bands are also increasing in intensity during the storage over winter because during the aging process of the cell the number of partially lignified or even dead cells with lignified cell walls that strengthen the wall, is increasing (Roman et al., 2011b).

It was determined in previous studies that it is the carbohydrates from the storage organs that play an important role in development of geophytes. In Sparaxis grandiflora the mobilization of resources from parent corm during the establishment of the new season growth (April-August) plays a major role, since leaf development that begun in early April mainly based on the resources stored in the reserve organ, accounted for about 26 to $77 \%$ of the total plant biomass from May to September (Ruiters and McKenzie, 1994).
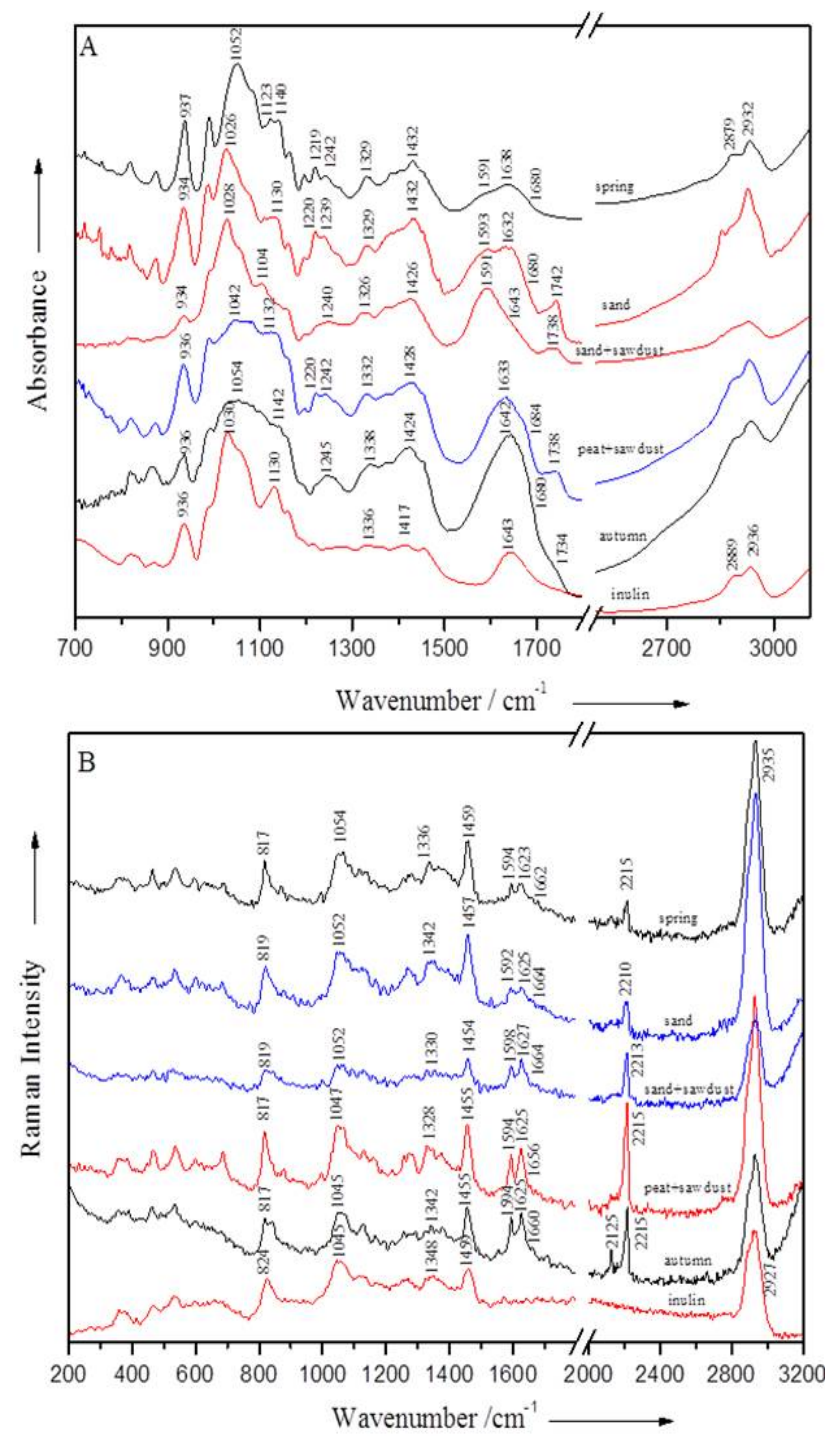

Fig. 2. FT-IR (A) and FT-Raman (B) spectra of 'Red Pygmy' cultivar's tuber, before and after storage over winter in different substrates. The inulin spectra are also presented for comparison purposes
Given the importance of the carbohydrates stored in the reserve organ for the vegetative development in the early season (Kamenetsky and Okubo, 2013) and also in the formation of the daughter corms of geophytes (Ruiters and McKenzie, 1994), it was settled that inulin levels, the main carbohydrate in Dablia (Machado et al., 1998) is an important biochemical indicator that needs to be researched in relation to winter storage conditions, in order to settle the most beneficial storage particularities that ensures good levels of inulin in spring before planting. As it was already determined in previous studies, storage conditions of tubers significantly affect the quality of tubers in relation to mass loss as it was observed for Dablia in previous studies (Ciobanu et al., 2015).

Further details about the structural changes of the tubers maintained over winter in different substrates can be obtained by investigating the FT-Raman spectra. Thus, by analyzing the Figures $1 \mathrm{~B}$ and $2 \mathrm{~B}$ one can identify all main vibrational bands of the inulin molecule located at 824, 1045, 1348, 1459 and $2927 \mathrm{~cm}^{-1}$ in the spectra recorded from root sections from both Dablia cultivars. The comparison of the spectra recorded from tubers maintained in different substrates reveals that inulin accumulation is particularly favoured by the sand substrate, as previously observed from FT-IR spectra analysis.

Besides the bands assigned to inulin vibrations one can see in the Raman spectra recorded on root sections some bands around $2210 \mathrm{~cm}^{-1}$, which are due to vibration from the polyacetylenes. Polyacetylenes are secondary metabolites that are biosynthesized by plants and act as important protective compounds against pathogens and pests (Roman et al., 2011a). They are formed from unsaturated fatty acids and are built from acetate and malonate units (Christensen and Brandt, 2006). Polyacetylenes are usually present in plants at a low concentration, but their level can increase as an induced response of the plant to pathogen invasion (Roman et al., 2011b).

By looking at the spectra (see Fig. 1B) one can see that the polyacetylene bands are present in all the spectra recorded from the 'Kenemerland' cultivar, the most enhanced intensity having the bands from the spectrum recorded on the tubers maintained in peat + sawdust followed by those from the spectrum of the tubers kept in sand + sawdust. The lowest intensity of these bands was observed in the spectrum recorded from tubers stored in sand, even lower than that from the spectrum recorded from tubers kept in no substrate. In the spectra recorded from 'Red Pygmy' cultivar (see Fig. 2B) the most enhanced polyacetylene bands were also recorded from tubers maintained in peat + sawdust, whereas the polyacetylene bands from the spectra recorded from tubers stored in sand and sand + sawdust have almost the same intensity as that from the spectrum recorded from tubers kept over winter without any substrate. Thus, one can assume that the peat + sawdust substrate favours the polyacetylene formation maybe because this kind of substrate facilitates the occurrence and growth of pathogens. Besides, one can also conclude that the polyacetylene level increase, which can be associated with the response to the pathogen invasion, is dependent on the cultivar type.

Furthermore, by analyzing the Raman spectra of the tubers one can notice the presence of the band around $1660 \mathrm{~cm}^{-1}$, which is attributed to the amide I vibration of the proteins, and the bands around 1595 and $1625 \mathrm{~cm}^{-1}$, due to the $\mathrm{C}=\mathrm{C}$ stretching vibrations from lignin and other phenolic 
464

compounds present in the samples. Phenolic compounds are also secondary metabolites like polyacetylenes that occur in various organs in most of the plant species. They consist of a substantial range of compounds having an aromatic ring with one or more hydroxyl substituents. It is also known that phenolic compounds play an important role in resistance of plant diseases (Schulz and Baranska, 2007). Among them, lignin, as we mentioned above (Perera et al., 2012) confers strength to the cell walls and resistance to degradation or pathogenic attacks (Perera et al., 2011). By looking at the Raman spectra (see Figs. $1 \mathrm{~B}$ and $2 \mathrm{~B}$ ) one can see that these bands are mostly enhanced in the spectra recorded from tubers maintained in peat + sawdust proving the existence of a higher content of lignin in these tubers and supporting the above conclusion according to that this type of substrate favours the pathogen's development.

\section{Conclusions}

The biometric parameters evaluation corroborated with the results of FT-IR and FT-Raman spectroscopic investigations applied in the present study allowed us to assess the changes induced by the storage conditions on the morphology and biochemical composition of some Dablia tubers preserved over winter in different substrates. The biometric measurements evidenced that the peat and sawdust substrate is the most beneficial for tubers preservation, whereas the sand substrate is the least suitable one, because it does not favor either the weight conservation or the tubers number per root preservation. On the other hand, the close analysis of the FT-IR and FT-Raman spectra of the tubers revealed that the inulin accumulation inside the tubers is positively influenced by the storage in the sand substrate, and depends on the cultivar type. Moreover, it was established that the substrate based on peat and sawdust favors the polyacetylene formation inside the tubers, most probably because this substrate facilitate the pathogens occurrence and development. It was also found that the polyacetylene concentration increase is dependent on the cultivar type.

\section{References}

Baranska M, Roman M, Dobrowolski JCz, Schulz H, Baranski R (2013). Recent advances in Raman analysis of plants: Alkaloids, carotenoids and polyacetylenes. Current Analytical Chemistry 9(1):108-127.

Barclay T, Ginic-Markovic M, Cooper P, Petrovsky N (2010). Inulin - a versatile polysaccharide with multiple pharmaceutical and food chemical uses. Journal of Excipients and Food Chemicals 1(3):27-50.

Bernal BH, Calle J, Duarte EQ, Pinzó R, Velásquez M (2005). Inulin from tubers of Dablia imperialis Roetz. Revista Colombiana de Ciencias Químico Farmacéuticas 34(2):122-125.

Christensen LP, Brandt K (2006). Bioactive polyacetylenes in food plants of the Apiaceae family: occurrence, bioactivity and analysis. Journal of Pharmaceutical and Biomedical Analysis 41(3):683-693

Ciobanu I, Buta E, Husti A, Cantor M (2015). Research regarding the influence of cultivar and storage substrate at Dablia variabilis cactus type. Agriculture-Science and Practice 95(3-4):197-203.

Deguchi A, Ohno S, Hosokawa M, Tatsuzawa F, Doi M (2013). Endogenous post-transcriptional gene silencing of flavone synthase resulting in high accumulation of anthocyanins in black dahlia cultivars. Planta237(5):1325-1335.

Derkacheva O, Sukhov D (2008). Investigation of lignins by FTIR Spectroscopy. MacromolecularSymposia 265(1):61-68.

Draghia L, Chelariu EL (2011). Floriculture. Ed. Ion Ionescu de la Brad Iași pp 252-253.

GierlingerN,Schwanninger M(2007). The potential of Raman microscopy and Raman imaging in plant research. Journal of Spectroscopy 21(2):6989.

Hakiki M, Agustine S, Yety MI, Puspa DL, Desak GSA (2015). Characterization of Inulin from Local Red Dahlia (Dablia sp.L) Tubers by Infrared Spectroscopy. International Symposium on Applied Chemistry 16:78-84.

Herrero AM, Carmona P, Jiménez-Colmenero F, Ruiz-Capillas C (2014). Polysaccharide gels as oil bulking agents: Technological and structural properties. Food Hydrocolloids 36:374-381.

Kamenetsky R, Okubo H (2013). Ornamental Geophytes: From Basic Science to Sustainable Production. CRC Press, Boca Raton Florida $\mathrm{p}$ 578.

Kaur N, Gupta AK (2002). Applications of inulin and oligofructose in health and nutrition. Journal of Biosciences 27(7):703-714.

Koruri SS, Banerjee D, Chowdhury R, Bhattacharya P (2014). Studies on prebiotic food additive (inulin) in indian dietary fibre sources-garlic (Allium sativum), wheat (Triticum spp.), oat (Avena sativa) and dalia (Bulgur). International Journal of Pharmacy and Pharmaceutical Sciences 6(9):278-282.

Kosasih W, Sri P, Diah R, Sri P (2015). Preparation of Inulin from Dablia Tubers. International Symposium on Applied Chemistry Procedia Chemistry 16:190-194.

Lara-Cortés E, Martín-Belloso O, Osorio-Díaz P, Barrera-Necha LL, Sánchez-López JA, Bautista-Baños S (2014). Antioxidant capacity, nutritional and functional composition of edible Dablia flowers. Revista Chapingo Serie Horticultura20(1):101-116.

Lord T (2003). The Gardener's Bible. Flora, Vol. 1 (A-K) Ed. Cassell, London, 4466.

Machado de Carvalho MA, Pinto MM, Figueiredo-Ribeiro RCL (1998). Inulin production by Vernonia herbacea as influenced by mineral fertilization and time of harvest. Brazilian Journal of Botany 21(3):1-8.

Muntean CM, Leopold N, Halmagyi A, Valimareanu S (2011). Ultrasensitive detection of genomic DNA from apple leaf tissues, using surface-enhanced Raman scattering. Journal of Spectroscopy 25(1):3343.

Nsabimana C, Jiang B (2011). The chemical composition of some garden Dablia tubers. British Food Journal 113(9):1081-1093.

Ohno S, Deguchi A, Hosokawa M, Tatsuzawa F, Doi M (2013). A basic helix-loop-helix transcription factor DvIVS determines flower color intensity in cyanic dahlia cultivars. Planta 238(2):331-43.

Perera PN, Schmidt M, Chiang VL, Schuck PJ, Adams PD (2012). Ramanspectroscopy-based noninvasive microanalysis of native lignin structure. Analytical and Bioanalytical Chemistry 402(2):983-987.

Perera PN, Schmidt M, Schuck PJ, Adams PD (2011). Blind image analysis for the compositional and structural characterization of plant cell walls. Analytica ChimicaActa 702(2):172-177. 
Roman M, Dobrowolski JC, Baranska M, Baranski R (2011a). Spectroscopic studies on bioactive polyacetylenes and other plant components in wild carrot root. Journal of Natural Products 74(8):1757-1763.

Roman M, Baranski R, Baranska M (2011b). Nondestructive Raman analysis of polyacetylenes in Apiaceae vegetables. Journal of Agricultural and Food Chemistry 59(14):7647-7653.

Ruiters C, McKenzie B (1994). Seasonal Allocation and Efficiency Patterns of Biomass and Resources in the Perennial Geophyte Sparaxis grandiflora subspecies fimbriata (Iridaceae) in Lowland Coastal Fynbos South Africa. Annals of Botany 74(6):633-646.

Saengthongpinit W, Sajjaanantakul T (2005). Influence of harvest time and storage temperature on characteristics of inulin from Jerusalem artichoke (Helianthus tuberosus L.) tubers. Postharvest Biology and Technology 37(1):93-100.
Schulz H, Baranska M (2007). Identification and quantification of valuable plant substances by IR and Raman spectroscopy. Vibrational Spectroscopy 43(1):13-25.

Sestras R, Ardelean M, Cordea M, Sestras A (2013). Biostatistics and forestry experimental technique. AcademicPres Cluj-Napoca(in Romanian).

Zimmermann B, Kohler A (2014). Shedding light on plant biology by Fourier transform infrared spectroscopy of pollen. Spectroscopy Europe 26(4):20-23.

Zubaidah E, Akhadiana W (2013). Comparative Study of Inulin Extracts from Dablia, Yam, and Gembili Tubers as Prebiotic. Food and Nutrition Sciences 4(11):8-12. 